\title{
Geografia e Google Earth na Sala de Aula: Proximidades, Diálogos e Aprendizagens
}

\author{
Luiz Martins Junior* \\ Guilherme Cardoso Estevão** \\ Rosa Elisabete Militz Wypyczynski Martins ${ }^{* * *}$
}

Resumo

Hoje utilizamos as tecnologias digitais para diversas atividades, sejam elas profissionais ou recreativas, por isso, pensamos em unir a ferramenta do Google Earth ao ensino da Geografia. Nesse contexto, o presente artigo tem por objetivo principal analisar as potencialidades e a relevância da utilização das tecnologias digitais, com foco específico na ferramenta Google Earth para a construção de uma carta postal fictícia abordando os conhecimentos e categorias da Geografia. No perscrutar dessa investigação, o estudo inserese numa abordagem epistêmica metodológica do tipo qualitativa e de natureza colaborativa, por meio da qual realizou-se uma prática pedagógica e um questionário aplicado para 27 estudantes de uma turma do nono do Ensino Fundamental de uma escola pública de Florianópolis/SC, em 2018. Os resultados apontaram, em linhas gerais, que os/as estudantes se mostraram acessíveis e flexíveis para a construção dos conhecimentos da Geografia escolar por meio de tecnologias digitais. Acompanhados dessas evidências, os resultados sinalizaram que os/as estudantes não possuem o contato frequente com essas tecnologias na disciplina de Geografia, por conta disso, relataram que a falta de metodologias mais interativas faz com que as aulas de Geografia se tornem descritivas e pouco interessantes.

Palavras-chave: ensino de geografia, tecnologias digitais, ferramenta do google earth.

\section{Geography and Google Earth in the Classroom: Proximities, Dialogues and Learning}

\begin{abstract}
Today we use digital technologies for various activities, be they professional or recreational, that's why we thought about joining the Google Earth tool to the teaching of Geography. In this context, the main objective of this article is to analyze the potential and the relevance of the use of digital technologies, with a specific focus on the Google Earth tool for the construction of a fictitious post card addressing the knowledge and categories of Geography. In the search for this investigation, the study is part of an epistemic methodological approach of a qualitative and collaborative nature, through which a pedagogical practice and a questionnaire applied to 27 students from a class in the ninth elementary school of a public school were carried out Florianópolis / SC, in 2018. The results showed, in general, that students were accessible and flexible to build knowledge of school geography through digital technologies. Accompanied by this evidence, the results signaled that students do not have frequent contact with these technologies in the discipline of Geography, because of this, they reported that the lack of more interactive methodologies makes Geography classes become descriptive and not very interesting.
\end{abstract}

keywords: geography teaching, digital technologies, google earth tool.

\footnotetext{
* Doutorando no Curso de Educação pelo Programa de Pós-Graduação em Educação FAED/UDESC, Florianópolis, Brasil. E-mail: luizmartins.jr@hotmail.com.

*** Graduando em Geografia pela Universidade do Estado de Santa Catarina - UDESC. Bolsista do Laboratório de Estudos e Pesquisas de Educação em Geografia - LEPEGEO.

**** Doutora em Geografia; Professora da área do ensino de Geografia, supervisora de estágios do curso de Geografia Licenciatura da FAED/UDESC; Coordenadora do LEPEGEO - Laboratório de Estudos e Pesquisas de Educação em Geografia; membro do LABTATE/UFSC; Coordenadora PIBID Geografia da FAED/UDESC; Professora do curso de Pós-Graduação em Geografia da UFSC, Florianópolis, Brasil. Email: rosamilitzgeo@gmail.com.
} 


\section{Primeiros Clics}

As inovações tecnológicas têm evoluído constantemente, por conta disso, marcam e demarcam a sociedade contemporânea e possibilitam ampliar a comunicação em rede e as inovações sociais, produtivas, temporais e espaciais, principalmente, a partir da passagem do século XX para o XXI. Isso resulta em alterações na vida em sociedade, como também no que diz respeito aos aspectos socioculturais, geopolíticos, ambientais, econômicos e, por conseguinte, educacionais. Os avanços tecnológicos atingem o campo da Educação em geral em seus diversos níveis, etapas e componentes curriculares. No caso deste trabalho, importa-nos um componente em específico que vem ganhando corpo teórico e metodológico desde as últimas décadas do século $\mathrm{XX}$ e, igualmente, incorporando as tecnologias no seu escopo acadêmico e profissional, qual seja, o ensino de Geografia.

Convictos com as mudanças substanciais e significativas resultantes do avanço das tecnologias digitais, como também, certos de que as pesquisas acadêmicas contribuem sobremaneira para mudanças efetivas no fazer escolar cotidiano nas práticas do ensino de Geografia, trazemos neste texto uma experiência investigativa e, ao mesmo tempo, didática-metodológica vivenciada no contexto do Programa Institucional de Bolsas de Iniciação à Docência (PIBID), por meio da Universidade Estadual de Santa Catarina - UDESC, no curso de Licenciatura em Geografia. Trata-se de uma experiência formativa que trabalhou com o uso do Google Earth como ferramenta didáticapedagógica na sala de aula envolvendo uma turma do nono ano dos anos finais do Ensino Fundamental da Educação Básica, na cidade de Florianópolis/SC, no segundo semestre de 2018, abordando o ensino de Geografia com enfoque na temática sobre a União Europeia.

A propósito de colocar em prática o uso da ferramenta digital, foi definido como principal objetivo analisar as potencialidades e a relevância da utilização das tecnologias digitais, com foco específico na ferramenta Google Earth para a construção de uma carta postal fictícia abordando os conhecimentos da Geografia, portanto, definimos para a prática três objetivos específicos: (1) Propor uma prática pedagógica com o uso Google Earth na sala de aula para ensinar o conteúdo sobre "os países não alinhados à união europeia"; (2) compreender como se dá a relação do estudante e o uso do Google Earth 
como uma ferramenta de aprendizagem; (3) avaliar o processo de construção dos conteúdos geográficos por meio do uso Google Earth. Para atingir os objetivos propostos, estipulou-se a seguinte questão: Como o Google Earth pode auxiliar na dinâmica metodológica das aulas de Geografia?

A abordagem epistêmica metodológica adotada para esta pesquisa foi do tipo qualitativa, na modalidade colaborativa, com base na observação e na aplicação do Google Earth como instrumento de abstração do conhecimento geográfico, que resultou na produção de uma carta geográfica postal fictícia com o intuito de avaliar os conhecimentos adquiridos durante o decorrer do processo de construção do conhecimento geográfico. Além disso, foi aplicado um questionário, com a finalidade de constatar como se deu a relação Estudante-Tecnologia conforme os objetivos propostos.

Para tanto, este texto está organizado em três partes principais: o marco inicial localiza-se numa discussão centrada no enquadramento conceitual sobre as considerações da ferramenta Google Earth e sua relação na construção dos conhecimentos e categorias operantes da Geografia escolar. Seguido dessa discussão teórica, realizamos a apresentação da natureza metodológica adotada nesta investigação, pontuando os sujeitos que participaram e o universo da prática pedagógica. Por fim, nos detemos à leitura da aplicação do questionário, com destaque para a inserção das tecnologias digitais no ensino de Geografia e no processo da prática pedagógica realizada com os estudantes envolvidos.

Considerações sobre a Ferramenta Google Earth e sua relação com a Geografia Escolar

Neste trabalho, tomamos a categoria tecnologia como promotora de conhecimento e como representação de recursos e/ou ferramentas tecnológicas em favor de processos de ensino e de aprendizagem. Do ponto de vista do campo educacional, as tecnologias digitais, a priori, são entendidas, neste artigo, como artefato mediador para construção do conhecimento e da aprendizagem e não como auxílio complementar da prática educativa, de entretenimento ou motivação dos/as estudantes ou como ocupação de tempo nos laboratórios de informática (SOUZA-NETO, LUNARDI-MENDES, 2017).

Sua utilização, no caso do ensino de Geografia, pode ser vislumbrada tanto como uma possibilidade ao processo de ensino e aprendizagem quanto para despertar o olhar do/a professor/a para sua importância em contribuir na superação de barreiras e exclusão 
digital existentes no âmbito escolar. Nesse sentido, Oliveira e Garcia (2019) advertem sobre a consensualidade de que, fazendo o uso dos múltiplos dispositivos, plataformas e ambientes digitais de maneira correta, dirigida e planejada, os/as estudantes podem aprender conceitos, conteúdos e temáticas que fazem parte da estrutura do currículo de diferentes áreas do conhecimento, neste caso, os saberes e conhecimentos da Geografia escolar. A inserção das tecnologias se dá no sentido de pensar em uma Geografia que possibilite travar discussão sobre a conformação da totalidade-mundo atual, mostrando que as tecnologias digitais são importantes para mediar o ensino de Geografia quando se trabalha a formação do/a estudante para o mundo contemporâneo.

Nesse âmbito, a proposta do uso das tecnologias para mediar a aprendizagem em sala de aula contribui para qualificar o ensino de Geografia, estimular o interesse dos/as estudantes em fazer uso dos múltiplos ambientes de aprendizagens, dos artefatos digitais, das mídias e das plataformas educacionais, superando, dessa forma, as limitações impostas pelas aulas expositivas, pelo currículo tradicional e pela cultura na qual a escola está imersa (SANTOS, PINTO, GALDINO, 2015).

Dos ambientes de aprendizagens, deriva a ferramenta Google Earth $^{l}$, que é objeto de investigação e prática deste artigo. O Google Earth é uma ferramenta popularmente conhecida pelos/as professores/as de Geografia, embora não muito utilizada, porque exige alguns conhecimentos técnicos e operacionais. Em grande parte, os/as professores/as que se encontram na sala de aula não possuem esses conhecimentos, por isso, encontram algumas dificuldades ou, como ocorre com frequência, demonstram resistência em lidar com a ferramenta (MARTINS-JUNIOR et al., 2019). Contudo, entendemos que o conhecimento sobre a ferramenta por partes dos/as professores/as e seu domínio no ensino não caminham em pé de igualdade, levando à necessidade de uma reformulação formativa continuada, à luz do uso pedagógico das tecnologias digitais nas escolas e suporte de computadores e redes de Internet.

Quanto à ferramenta em si, a arquitetura do Google Earth, por natureza, apresenta um mosaico de possibilidades e potencialidades que podem contribuir para um ensino de Geografia mais atrativo, instigante e repleto de aprendizagens. A ferramenta encontra-se disponível na rede do ciberespaço gratuitamente para uso e consulta, pessoal e/ou pedagógica, de informações, dados e imagens sobre a localização do espaço geográfico

\footnotetext{
${ }^{1}$ http://earth.google.com.
} 
cartograficamente representado, tanto na projeção local quanto na escala global. Não obstante, a ferramenta possibilita a visualização de mapas, os aspectos humanos por meio das imagens de satélites e 3D, fotografias aéreas e sistema de informação geográfica, bem como, possibilita aumentar a visualização (dar o zoom) em diferentes escalas geográficas. Nesse contexto, Giordani (2014, p. 167) acrescenta a possibilidade do usuário pesquisar e delinear as “[...] próprias rotas, pontos e áreas, gerar comentários e compartilhar o link do mapa criado".

O Google Earth fornece uma riqueza de imagens tridimensionais que permitem ao estudante, através da percepção visual, analisar virtualmente o espaço geográfico em diferentes escalas geográficas. Isto é, permite a esse sujeito observar a Geografia física, paisagística e arquitetônica do bairro, da cidade e/ou do país, tornando-se um explorador, ou seja, um pedestre virtual de informações, de dados e imagens do local analisado (GIORDANI, 2014). Mediante a definição do conteúdo pelo/a professor/a, é possível que o/a estudante realize a interpretação do conteúdo sobre diferentes ângulos e formas e, até mesmo, perceba como ele se constitui e organiza física, social e culturalmente no espaço geográfico.

Além disso, nesse entendimento, Pinto et al. (2016) destacam a possibilidade de o/a estudante relacionar o conteúdo com outras dinâmicas socioespaciais, como, por exemplo, analisar o lugar onde reside, as moradias e pavimentações, a vegetação, os rios, as vulnerabilidades ambientais e, ainda mais, relacionar esse lugar com outro espaço que apresenta características culturais, geológicas, sociais e ambientais semelhantes. Giordani (2014) justifica que essa possibilidade de associações e comparações de um lugar com outro proporciona a leitura e a relação do mundo em sua espacialidade e totalidade, de forma enfática, detalhada e colaborativa.

\section{Metodologia - Contexto da Pesquisa}

$\mathrm{O}$ estudo das tecnologias digitais, em particular a ferramenta Google Earth e o ensino de Geografia são pontos que se conectam, intersecionam e se complementam nessa investigação educativa. Para entender a relação, a usabilidade e as potencialidades das tecnologias no ensino de Geografia, realizamos uma prática pedagógica do ponto de vista investigativo, abordando os conteúdos de Países não alinhados à União Europeia por meio 
da ferramenta Google Earth. A decisão do conteúdo foi do professor regente da turma, conforme previsto no planejamento curricular da disciplina. Participaram da pesquisa vinte e sete estudantes, sendo quatorze autodeclarados do gênero masculino e treze do gênero feminino, com idades entre onze e treze anos, de uma turma do nono ano do Ensino Fundamental II da cidade de Florianópolis/SC, no ano de 2018.

A coleta de dados realizou-se por meio de uma pesquisa colaborativa de cunho qualitativo. A natureza da pesquisa colaborativa, segundo Cavalcanti e Souza (2014, p. 141), inspirados em Ibiapina (2008), constrói-se por duas direções que se entrecruzam "[...] uma da integração do pesquisador na construção de propostas junto com o/a professor/a, no interior da escola, e a outra da integração e a aprendizagem colaborativa dos participantes na prática pedagógica". Nesse âmbito, observamos que a pesquisa em tela nos possibilitou gerar e propor para a Geografia escolar propostas pedagógicas digitais que garantam decisivamente a participação e a colaboração de todos os/as estudantes na construção de conhecimentos e dos conceitos operantes da Geografia. Significa dizer que as enunciações, os tensionamentos e as potencialidades presentes na pesquisa colaborativa atuam como elementos constitutivos na construção e edificação dos temas, fenômenos e espacialidades geográficas.

Noutras palavras, entende-se que pesquisas dessa natureza qualificam novos caminhos para ensinar Geografia colaborativamente sob a ótica do universo digital e, sobretudo, constitui-se como proposta metodológica que possibilita lidar, integrar e valorizar as relações heterogêneas presentes no (sub)espaço geográfico que é a sala de aula, por meio das combinações, trocas coletivas, agrupamentos, interações em rede e colaborações de cada um e de todos durante o processo de ensino e aprendizagem.

Logo, o enfoque da pesquisa qualitativa na modalidade colaborativa, ao proporcionar o contato direto e pleno do/a pesquisador/a com a situação investigada, permite também ampliar o entendimento das relações e processos estabelecidos entre os sujeitos participantes e os significados das ações presentes nas práticas escolares e na dinâmica que ocorre no microespaço da sala de aula, neste caso, a partir da abordagem do Google Earth no ensino de Geografia.

A partir dos desdobramentos dos princípios teórico-metodológicos da pesquisa qualitativa com enfoque colaborativo, a investigação empírica respeitou três momentos principais: 1) o estudo e a discussão em questão do conteúdo, 2) a prática pedagógica 
baseada no uso da ferramenta Google Earth e 3) aplicação de um questionário para os sujeitos envolvidos. Relativo à segunda etapa do percurso investigativo, apresentamos a prática pedagógica na sessão seguinte.

\section{Prática Pedagógica em Ação}

A realização da atividade didático-pedagógica objetivou elaborar uma carta postal fictícia, abordando os conteúdos de Países não alinhados à União Europeia, por meio do uso da ferramenta Google Earth e sites seguros disponíveis no ciberespaço. O desenvolvimento da proposta pedagógica passou pelas seguintes etapas: primeiro, foi realizado um processo de explicação, contextualização e problematização acerca do conteúdo bloco econômico europeu e suas relações com os países não pertencentes. Isso se deu em aula expositiva-dialogada, baseada no livro didático e nas informações colhidas da rede do ciberespaço.

No segundo momento da aula, foi apresentada aos estudantes a estrutura arquitetônica da ferramenta Google Earth, composta por suas diferentes interfaces de acesso e coleta de dados, imagens e informações geográficas e cartográficas. Também foi abordado como criar uma carta postal fictícia (respeitando o mesmo modelo tradicional de correspondência), com o objetivo de escrever uma carta geográfica acerca do conteúdo em questão. Feito esse encaminhamento, foi proposto para a turma a formação de equipes e a divisão dos países para a escrita de uma carta fictícia, contendo os seguintes requisitos: dados cartográficos, aspectos físicos, econômicos e culturais e o motivo pelo qual o país não faz parte do bloco econômico da União Europeia.

$\mathrm{Na}$ terceira etapa, os/as estudantes foram encaminhados para o laboratório, com o propósito de realizar a pesquisa in loco, com vistas a coleta de dados, imagens e informações geográficas no ambiente da ferramenta do Google Earth para a produção da carta fictícia.

Após esse procedimento de investigação virtual, a quarta etapa caracterizou-se pelo momento de orientação da escrita da carta e a definição do destinatário para o qual ela seria entregue. Para proporcionar aos estudantes um primeiro contato com cartas postais, foram escritas e lidas pelo pesquisador algumas dessas, com a intenção de inspirar a criatividade e aflorar a imaginação, assimilando os conteúdos em questão. Assim, as 
equipes foram desafiadas a não só dar-se conta dos conteúdos pesquisados na escrita, como também de narrar os conteúdos de forma agradável, atraente e poética. Terminando essa etapa, foram efetuadas trocas das cartas, acompanhadas pelas leituras e comentários sobre as histórias narradas.

\title{
A Prática Pedagógica sob o Olhar dos/as Estudantes
}

A aplicação do questionário aconteceu na sala de aula com o auxílio do professor regente da disciplina de Geografia e na companhia do pesquisador, na última semana de outubro de 2018. O objetivo foi o de saber a opinião dos/as estudantes sobre a prática pedagógica. O questionário pontuou algumas questões para expressar o ponto de vista sobre a atividade pedagógica da qual participaram, bem como, identificar fatores que contribuíram para o aprendizado. Acredita-se que mapear a opinião dos/as estudantes foi importante para que se possa compreender a relação que eles estabeleceram com as tecnologias digitais para aprender Geografia. Vejamos as respostas dadas às questões:

\section{O que você achou da atividade pedagógica abordando o uso das tecnologias} educativas? (Se boa ou ruim e por quê?). Os/as estudantes gostaram da atividade no geral, destacaram o benefício e a comodidade da tecnologia, porém reclamaram da conexão à Internet da escola. Dentre as respostas se destacam:

\begin{abstract}
"Achei bom, pois com a tecnologia fica tudo mais fácil, já que estamos na era da tecnologia avançada". "Achei interessante e bom, porque pude me aprofundar mais nos assuntos". "Sim, o uso da tecnologia nos ajuda a conhecer as coisas de uma maneira muito mais fácil. Por exemplo, podemos ver e saber sobre outro país sem sair do nosso próprio". "Boa, pois assim nós pudemos saber sobre os países com mais facilidade, sem precisar viajar". "Boa, porque pudemos aprender muito na internet, um pouco ruim por causa da conexão que estava fraca". "Boa, agregadora, interessante porque não estamos acostumados fazer atividades com o uso das tecnologias". "Achei boa, porque aprendi utilizar as tecnologias para aprender geografia, pois só com o uso do livro não aprendemos muito".
\end{abstract}

Relembra-se aqui que esses estudantes são da chamada Geração $Z^{2}$, segundo Fava (2014), que nunca conceberam o mundo sem computador ou Internet. Eles não viram a globalização surgir, ou seja, viveram e cresceram com ela a vida toda, desse modo, a

\footnotetext{
${ }^{2}$ Geração Z, remete aos sujeitos que nasceram na era das tecnologias, no período de 1990 a 2010 . Tal geração é caracterizada pela velocidade tecnológica, conectada 24 horas pelas redes sociais, com pessoas pragmáticas, donas de uma personalidade flexível, com laços fracos e vulneráveis (FAIVA, 2014).
} 
tecnologia digital sempre fez parte da vida da maioria desses estudantes. Por conta dessa característica, criaram novas habilidades e competências. É na escola, porém, que eles precisam deixar tudo isso de lado e aprender de uma forma diferente daquela a que estão habituados em casa ou em outro lugar que não a escola. Embora isso, percebeu-se que o uso da ferramenta para estudar os conhecimentos da Geografia por parte dos/as estudantes se deu de forma ágil, positiva, empolgante e motivacional.

Cumpre evidenciar que a prática pedagógica feita com o emprego das tecnologias digitais caracterizou-se, em linhas gerais, como atividade que despertou o interesse dos/as estudantes e possibilitou conexões entre os conteúdos e conceitos trabalhados. Também é importante destacar que, além dos saberes da Geografia, a prática potencializou a aprendizagem dos conceitos e conhecimentos da cartografia escolar.

É preciso chamar atenção ao seguinte fator: para desenvolver um planejamento de aula com uso das tecnologias, faz-se necessário que tenhamos as condições mínimas de infraestrutura, tais como computadores e rede de Internet nas escolas de Educação Básica. A falta desses aparatos se torna obstáculo ao trabalho do/a professor/a em suas práticas em sala de aula com os chamados nativos digitais ${ }^{3}$. De acordo com Santos e Domingues (2015), em grande parte, os problemas relativos ao uso das tecnologias digitais no setor pedagógico se dão por duas razões pontuais: a primeira, encontra-se na ausência de aparato tecnológico e informatizado, o que dificulta o trabalho pedagógico e, a segunda situação, deriva de que, em grande medida, os/as professores/as que atuam nas escolas com as práticas educativas são considerados "migrantes digitais", pois nasceram sob o signo da cultura analógica e não possuem fluência digital ${ }^{4}$, o que pode dificultar o uso das tecnologias para o desenvolvimento de práticas em sala de aula. Souza-Neto e Lunardi-Mendes (2017) destacam a importância da fluência digital por parte do/a professor/a para que este tenha segurança no uso pedagógico das tecnologias em sala de aula.

A quantidade e o nível dos usos pedagógicos das TDIC na escola são diretamente proporcionais à fluência digital do professor que, por sua vez, está

\footnotetext{
${ }^{3}$ De acordo com Prensky (2001) os nativos digitais são as crianças que nasceram na era das tecnologias digitais, os quais não demonstram dificuldades de lidar com as tecnologias, pelo contrário, demonstram capacidade natural de realizar múltiplas tarefas por meio das tecnologias.

${ }^{4}$ Souza-Neto e Lunardi-Mendes (2017) conceito de fluência digital é traduzido como uma linguagem e conhecimento específico apropriado pelo professor para compreender, reconhecer e aplicar as tecnologias digitais nas práticas pedagógica.
} 
subalterna à sua fluência pedagógica. Por isso, estabelecemos que é preciso aprender a usar as TDIC, se aventurar pelo processo de apropriação dessas tecnologias em busca da sua fluência digital, para depois, então, inseri-las em contexto didático-pedagógico (SOUZA-NETO, LUNARDI-MENDES, 2017. p. 520).

Ou seja, o primeiro passo em direção a uma educação transformadora a partir das tecnologias digitais é dominá-las, conhecê-las bem o suficiente para que quando seja necessário utilizá-las em favor da Educação, isso se torne possível. Somente após essa fase de experimentação com as tecnologias digitais é possível trabalhá-las no contexto da Educação.

Você acredita que a tecnologia ajudou a compreender os conteúdos sobre os países que não pertencem ao bloco da União Europeia? Os/as estudantes colocaram a importância da tecnologia como facilitadora para conhecerem tal conteúdo. Evidenciamse, na sequência, as respostas:

\begin{abstract}
"Sim, se não fosse pela tecnologia digital, não teríamos conseguido tais informações sobre os países". "Sim, eu compreendi mais e achei bem interessante, sem contar que é bem mais divertido". "Sim, sem a tecnologia todo mundo ia precisar viajar ou falar com quem já viajou para o país". "Sim, pois muitas coisas que não encontraríamos nos livros e com a tecnologia conseguimos desvendar melhor os países". "Claro, pude vivenciar uma ampla gama da situação cultural, social, política e ambiental dos países". "Acredito muito porque pude visualizar diferentes imagens sobre as situações geográficas do país que fiquei responsável". "Acredito, pois pude não só estudar o país mas também relacionar a Geografia dele com outros países e até mesmo com onde moramos, como por exemplo a questão do meio ambiente". "Sim, ajudou muito aprender os conteúdos e, sobretudo, facilitou para coletar as informações da internet para elaborar a carta postal geográfica".
\end{abstract}

Como se pôde perceber, os/as estudantes afirmam que o uso da tecnologia nas aulas contribui para mediar a aprendizagem, na coleta de informações e na construção do conhecimento. Segundo Fava (2014), a Educação contemporânea está no meio de todas as mudanças tecnológicas recentes que mudaram a caracterização do espaço e do tempo. Criou-se uma nova cultura interativa e participativa, mudou-se, então, o modo de aprender e ensinar com a presença e o emprego das tecnologias digitais.

Além destes, percebemos nas avaliações dos/as estudantes as potencialidades das tecnologias para vivenciar e experenciar os conhecimentos, neste caso, os da Geografia escolar, em diferentes escalas geográficas: local, regional e global. As afirmações apontadas pelos/as estudantes também indicaram que aprender a Geografia de forma 
diferente, colaborativa e virtualmente fora dos muros e paredes que cercam o espaço escolar contribui para ampliar os horizontes e vivenciar formas distintas e plurais de aprendizagem.

As potencialidades do uso das tecnologias se concretizam nos depoimentos dos/as estudantes quando operam com autoria e autonomia as tecnologias. Isso possibilita o acesso aos recursos informativos e imagéticos sob diferentes linguagens, concepções e representatividades para subsidiar a construção das cartas postais fictícias. Além do mais, as falas nos guiaram para o entendimento de que as tecnologias assumiram também o papel de mediadoras/facilitadoras e/ou como um meio para a realização da atividade de pesquisa e construção da carta postal abordando o conteúdo sobre os países não pertencentes à União Europeia.

Você teve alguma dificuldade em realizar a consulta no Google Earth, ou identificar e capturar alguma imagem da ferramenta tecnológica, bem como, coletar informações no ciberespaço? Justifique. Todos responderam que "Não", destacando:

\footnotetext{
"Não, porque o Google Earth é muito fácil de utilizar e ver fotos de lugares pelo mundo". "A maior dificuldade foi a conexão que não deu nenhuma contribuição para ajudar com a pesquisa". "Sim, tive alguma dificuldade pois a internet estava muito lenta". "Não, é uma ferramenta acessível aquecida de uma riqueza de informações geográficas". "Não, porque a ferramenta apresenta em sua estrutura informações fáceis que nos guia para elaborar trajetos e criar mapas". "Não, pelo fato de ser acessível, ilustrativo e interativo". "Não, porque os campos são colaborativos e ilustrativos". "Não, é muito fácil usar as imagens e coletar informações, bem que professor podia trabalhar mais com a gente abordando o Google Earth". "Pelo contrário, é facilitadora, a única dificuldade foi só na primeira vez em como capturar a imagem e selecionar dados". "Não, tive nenhuma dificuldade, pelo contrário, foi facilitadora para selecionar imagens e informações para construir a carta".
}

A partir das falas dos participantes, é possível depreender que a ferramenta Google Earth é uma tecnologia digital que imprime, no seu uso, a supremacia da acessibilidade, operacionalidade e flexibilidade para o modo de construir os conhecimentos geográficos. Cabe ainda destacar, a partir da leitura das respostas, a facilidade para operar com a arquitetura estrutural da ferramenta. Tais colocações revelam o quanto a ferramenta serve como meio de aprendizagem, com vistas na mobilização dos conceitos, conteúdos e temáticas que integram a genealogia do currículo de Geografia.

Do ponto de vista da arquitetura, os/as estudantes concordaram que o Google Earth consiste em uma ferramenta que reserva potencialidades de interfaces de 
aprendizagem que possibilitam a criação e aplicação de mapas cartográficos (rotas, trajetos, caminhos) e coletas de imagens geográficas (em forma de relevo ou satélite). Nessa perspectiva, Tonini et al. (2014, p. 161) afirmam que as versatilidades, operacionalidades e potencialidades dessa ferramenta e suas múltiplas linguagens na aprendizagem geográfica correspondem à relação íntima das “[...] linguagens gráficas com as linguagens textuais". É relevante apontar que a relação textual e gráfica é importante para mediar o processo de ensino e aprendizagem, contribuindo para articular os movimentos e as informações entre conteúdos e conceitos trabalhados no ensino de Geografia.

Outro aspecto importante encontrado nos depoimentos dos/as estudantes foi a dimensão da experiência como elemento marcado de descobertas e valorização do Google Earth como ferramenta de aprendizagem que possibilita explorar e ampliar os canais de comunicação (navegador Google, plataformas, ambientes digitais, aplicativos, entre outros) durante o processo de coleta, escolhas e preferências de informações e dados sobre os aspectos ambientais, políticos, econômicos, culturais e geográficos para a elaboração das cartas postais fictícias.

Você acredita que aprender de forma "diferente", "tecnológica", é um caminho mais acessível para entender os conhecimentos geográficos? Por quê?

Decorrente das respostas apresentadas, todos os/as estudantes concordaram que "Sim", justificando o que é aprender conectado:

\footnotetext{
"Porque é mais divertido, aprender sem tecnologia se torna chato e cansativo". "Porque quando você vê os lugares fica mais fácil de entender o conteúdo". "Acredito, porque com o uso da tecnologia é mais fácil e útil, faz com que o seu desenvolvimento seja maior". "Super válido e enriquecedor fazer o uso das tecnologias para aprender Geografia que é uma disciplina tradicional". "Sem sombra de dúvidas, as tecnologias trouxeram nova vida para aprender, pena que o professor não faz o uso, pois eu adoraria aprender mais com elas". "Acredito que sim, porque com as tecnologias consigo assistir vídeos, ler imagens, aplicativos, acessar jogos geográficos e, até mesmo, o google Earth, que possam me ajudar aprender mais o conteúdos de Geografia". "Sim, mas o professor não faz o uso e, com isso, poderíamos aprender mais o conteúdo de forma profunda". "Sim, como por exemplo, a proposta realizado com o professor da faculdade por meio das tecnologias me possibilitou aprender mais do que se fosse com o professor em sala de aula".
}

Com base nos registros, podemos constatar que a atividade pedagógica planejada com o uso das tecnologias contribuiu para despertar maior interesse e motivação para aprender Geografia, disciplina que apresenta um rol de conhecimentos específicos e 
complexos que exigem atenção, leitura e concentração e, muitas vezes, é pautada num ensino e aprendizagem sob a ótica de técnicas convencionais de confecção de maquetes, roteiros de casa à escola, cópias de mapas e de exercícios mnemônicos de elencar terminologias de bairros, cidades e capitais. Os depoimentos dos/as estudantes coadunam com as palavras de Tonini (2013), de que as tecnologias presentes na cultura escolar de forma direta ou indireta promovem outras formas educativas de aprendizado, ora fazendo uso de aplicativos, ambientes virtuais, plataformas educacionais, ora trabalhando com jogos digitais, explorando atividades colaborativas ou propondo pesquisa na rede do ciberespaço.

Também destacam o pouco uso das tecnologias digitais de ensino de Geografia. De acordo com os/as estudantes, podemos compreender que sentem a necessidade de aprender Geografia com a mediação das tecnologias digitais, pois estas apresentam opções de vídeos, imagens, aplicativos, jogos geográficos, como é o caso do Google Earth, que possibilita a visualização de fenômenos geográficos de qualquer parte do mundo. Visto por esse ângulo, Sales (2012) entende que a exploração das tecnologias digitais no ensino de Geografia é uma emergência, haja vista que elas tendem a ampliar a compreensão dos conhecimentos e conceitos geográficos por meio da manipulação de imagens, relações geográficas em diferentes escalas, simulações dos fenômenos geográficos, produção de mapas mentais e conceituais e jogos virtuais geográficos.

Oliveira, Garcia e Gonçalves (2019) destacam que o direito e acesso dos/as estudantes a aprenderem com/por meio das tecnologias digitais na Educação Básica tem sido cada vez mais prolongado pela escola, professores e, até mesmo, pelas políticas educacionais, porque os mesmos encontram-se asfixiados por uma inércia tradicional resistente e insegura, em contraponto às transformações tecnológicas ocorridas no espaço geográfico.

\section{Considerações Finais}

Com esta pesquisa buscamos analisar e compreender as potencialidades da utilização das tecnologias digitais, destacando a importância da ferramenta Google Earth para a construção dos conhecimentos da Geografia escolar. Conforme a leitura das respostas dos/as estudantes, é possível afirmar que a proposta realizada sintetizou que as 
viabilidades das tecnologias no espaço escolar exercem a pluralidade de ritmos e estilos de aprendizagens diferentes na sala de aula, e até mesmo contraria a crença tradicional de que todos aprendem da mesma forma.

Não obstante, esse “detour” ou movimento de interlocução do uso das tecnologias nas aulas de Geografia, neste caso por meio do uso da ferramenta Google Earth, revelou que a interatividade, o trabalho colaborativo, a criatividade, a autoria, a integração, a comunicação e o empoderamento são peças-chave quando as práticas pedagógicas assumem postura coletiva, planejada, sistematizada, estruturada e organizada, portanto consoante com a realidade social, familiar, geográfica e econômica de todos os/as estudantes envolvidos na ação pedagógica.

Com base ainda na utilização do Google Earth na prática pedagógica, podemos destacar que a ferramenta nos forneceu elementos e possibilidades significativas para trabalhar o conteúdo União Europeia que integra o componente curricular de Geografia. Do ponto de vista didático-metodológico, essa experiência pode se constituir numa referência de ação pedagógica importante para repensar e ressignificar o ensino de Geografia sob a ótica da contemporaneidade, pautada num trabalho colaborativo, interativo e compartilhado a partir do qual se reconheça e valorize a bagagem cultural e tecnológica que os/as estudantes levam para a sala de aula.

Do ponto de vista da participação dos/as estudantes durante o trabalho com o uso da ferramenta é preciso destacar que estes não se intimidaram diante da oportunidade de vivenciar outra experiência pedagógica, mesmo que a ferramenta Google Earth fosse desconhecida por muitos deles ou pouco utilizada por alguns para aprender os conhecimentos geográficos e cartográficos inerentes ao currículo de Geografia. Pelo contrário, se mostraram interessados e envolvidos na construção dos conhecimentos Geográficos por meio da elaboração das cartas fictícias.

Durante o processo de troca e socialização das cartas, vimos surgirem cartas repletas de palavras específicas e conceitos operantes da Geografia, sendo isso importante e significativo para a formação do pensamento geográfico dos estudantes. Isso reforça a importância de ampliar o acesso do uso das tecnologias nas práticas pedagógicas em sala de aula como forma de abrir horizontes culturais, evitando o distanciamento entre a cultura oferecida pela escola e a cultura digital vivenciada por crianças e jovens que frequentam as escolas de Educação Básica. 


\section{Referências}

CAVALCANTI, Lana de Souza.; SOUZA, Vanilton Camilo de. A pesquisa colaborativa na formação de professores de Geografia e seus desdobramentos no ensino. In: MARTINS, Rosa Elisabete M. Wypyczynki (Org.). Ensino de Geografia no contemporâneo: experiências e desafios. Santa Cruz do Sul: EDUNISC, 2014.

GIORDANI, Ana Claudia. Aprender Geografia: a vivência como metodologia. In: GIORDANI, Ana Claudia; SILVIA, Vanessa Oliveira da; TONINI, Ivaine Maria. Tecnologia de informação e comunicação disponíveis no ciberespaço para ensinar e aprender geografia. Porto Alegre: Evangraf, 2014.

IBIAPINA, Ivana Maria Lopes de Melo. Pesquisa colaborativa investigação, formação e produção do conhecimento. São Paulo. Liber livros, 2008.

MARTINS-JUNIOR, Luiz.; et al.. Explorando a ferramenta Google My Maps como ferramenta pedagógica no ensino de Geografia numa Escola Secundária em Portugal. In: HORTAS, Maria João.; DIAS, Alfredo. (Org.) Enseñar y aprender didáctica de las ciencias sociales: la formación del profesorado desde una perspectiva sociocrítica. Editora: Portugal, 2019.

OLIVEIRA, Denilton Silveira; GARCIA, Luciane Terra dos Santos; GONÇALVES, Luiz Marcos Garcia. Políticas de formação continuada de professores: inovação para uso da robótica como recurso pedagógico. Revista Linhas. Florianópolis, v. 20, n. 43, p. 102131, maio/ago. 2019.

PINTO, Bismarque Lopes; [et al.]. O Google Earth e a maquete em sala de aula: Geografia Escolar e aprendizagem geográfica. In: PORTUGAL, Jussara Fraga; OLIVEIRA, Simone Santos de; MEIRELES, Mariana Martins de; SOUZA, Hamilton Ribeiro de. (Org.) Geografia na sala de aula: linguagens, conceitos e temas. Curitiba: CRV, 2016.

PRENSKY, M. Nativos digitais, imigrantes digitais. 2001. Disponível em: http://www.colegiongeracao.com.br/novageracao/2_intencoes/nativos.pdf. Acesso em: 9 Jun. 2019.

SALES, Mary Valda Souza. Novas linguagens na potencialização da prática docente: as tecnologias, o ensino e a formação do professor (a) de Geografia. In: PORTUGAL, Jussara Fraga.; CHAIGAR, Vânia Alves Martins (Orgs.). Cartografia, cinema, literatura e outras linguagens no ensino de geografia. 1. ed. - Curitiba, PR: CVR, 2012.

SANTOS, Maria Francineila Pinheiro dos.; PINTO, Márcio Victor Moura.; GALDINO, Vinícius Higino. O facebook no ensino de Geografia: desafios e possibilidades. In: SACRAMENTO, Ana Claudia., et al. (Org.) Ensino de Geografia: produção do espaço e processos formativos. 1. ed. - Rio de Janeiro: Consequência, 2015. 
SOUZA-NETO, Alaim.; LUNARDI-MENDES, Geovana Mendonça. Os usos das tecnologias digitais na escola: discussões em torno da fluência digital e segurança docente. Revista e-Curriculum, São Paulo, v. 15, n. 2, p. 504-523 abr./jun. 2017.

TONINI, Ivaine Maria. Movimentando-se pela Web 2.0 para ensina Geografia. In: CASTROGIOVANNI, Antônio Carlos; TONINI, Ivanie Maria; KAERCHER, Nestor André. (Org.) Movimentos no ensino de geografia. Porto Alegre: Imprensa Livre: Compasso Lugar-Cultura, 2013.

Kaercher, N., Giordani, A. C., Castrogiovanni, A. C., Costella, R. Z. Aprender a ensinar Geografia: a vivência como metodologia. Porto Alegre: Evangraf, 2014.

Recebido em: 22 jun. 2019.

Aceito em: 10 fev. 2020. 